\title{
Aspectos jurídicos del delito de aborto en Bucaramanga, 1930-1946*
}

\section{Cristina Isabel Crespo Valero *}

Recibido: 14 de febrero de 2017

Enviado a pares evaluadores: 25 de febrero de 2017

Aprobado por pares evaluadores: 7 de abril de 2017

Aprobado por Comité Editorial: 25 de mayo de 2017 DOI: 10.22395/csye.v6n12a3

\section{RESUMEN}

Este artículo realiza una construcción histórica del aborto en Bucaramanga dentro del contexto de la república liberal, y tiene como objetivo principal presentar sus aspectos jurídicos. Para alcanzar este objetivo se exponen los diferentes enfoques interpretativos utilizados en la historiografía para el estudio del tema; se indaga sobre los antecedentes de las legislaciones nacionales que estuvieron vigentes durante el periodo estudiado $\mathrm{y}$, por último, se desvela el procedimiento penal llevado a cabo por las instituciones judiciales al momento de querer hacer efectiva la ley dentro del contexto social. Como conclusión se logró demostrar que el sistema judicial bumangués, aunque intentó seguir el procedimiento penal establecido en los códigos penales para vigilar y castigar el aborto, no logró su objetivo, ya que en la mayoría de los casos no se dejaban rastros ni huellas del delito y las investigaciones eran interrumpidas por la ineficacia de los funcionarios, por la precariedad de conocimientos médicolegales, y por la ausencia de herramientas científicas, lo que desencadenó toda una serie de circunstancias que influyeron en la imposibilidad de comprobar o conocer el cuerpo del delito.

Palabras clave: aborto; control social; delito; instituciones de justicia.

Este artículo toma los planteamientos principales desarrollados en la monografía de pregrado. Crespo, C. (2014). El aborto en la ciudad de Bucaramanga durante la repúbica liberal 1930-1946, Tesis de pregrado. Escuela de Historia, Universidad Industrial de Santander, Bucaramanga, Colombia.

** Historiadora de la Universidad Industrial de Santander. Se ha desempeñado como docente e investigadora en instituciones de educación media y universitaria. Correo electrónico: cristinacrespovalero@gmail.com 


\section{Legal aspects of abortion crime in Bucaramanga, 1930-1946}

\section{ABSTRACT}

This paper makes a historical construction of abortion in Bucaramanga within the context of the liberal republic, and its main objective is to present its legal aspects. In order to achieve this objective, different interpretative approaches used in historiography for studying the topic are stated; the background of national laws in force during the period studied, is investigated and, finally, the criminal procedure carried out by the judicial institutions at the moment of making the law effective within the social context is revealed. In conclusion, it was possible to demonstrate that judicial system in Bucaramanga, although tried to follow the criminal procedure established in criminal codes to monitor and punish abortion, did not achieve its objective, since in most cases no traces of the crime were left and the investigations were interrupted by the inefficiency of the officers, by the precariousness of medicallegal knowledge, and by the absence of scientific tools, which unleashed a whole series of circumstances that influenced the impossibility of finding the responsible of the crime.

Keywords: abortion; social control; crime; legal institutions.

\section{Aspectos jurídicos do delito de aborto em Bucaramanga, 1930-1946}

\section{RESUMO}

Este artigo realiza uma construção histórica do aborto em Bucaramanga (Colômbia) no contexto da República Liberal e tem como objetivo principal apresentar seus aspectos jurídicos. Para atingi-lo, expõem-se as diferentes abordagens interpretativas utilizadas na historiografia para o estudo do tema; questiona-se sobre os antecedentes das legislações nacionais que estiveram vigentes durante o período estudado e, por último, mostra-se o procedimento penal realizado pelas instituições judiciais no momento de querer tornar a lei efetiva no contexto social. Como conclusão, pôde-se demonstrar que o sistema judicial de Bucaramanga, embora tenha tentado seguir o procedimento penal estabelecido nos códigos penais para vigilar e castigar o abordo, não atingiu seu objetivo, já que, na maioria dos casos, não se deixaram rastros do delito, e as investigações eram interrompidas pela ineficácia dos funcionários, pela precariedade de conhecimentos médicolegais e pela ausência de ferramentas científicas, o que desencadeou uma série de circunstâncias que influenciaram na impossibilidade de comprovar ou conhecer o corpo do delito.

Palavras-chave: aborto; controle social; delito; instituições de justiça. 


\section{Introducción}

El principal objetivo de este artículo es construir una imagen histórica del aborto analizada desde los aspectos jurídicos en Bucaramanga dentro del contexto de la república liberal. Es importante resaltar que, aunque en la presente investigación no se tuvieron en cuenta los aspectos sociales, políticos y religiosos, se deja abierta la posibilidad para continuar cuestionándonos sobre ellos, ya que representan un factor significativo para comprender el problema del aborto que en nuestra actualidad es de amplio debate entre diversos sectores de la sociedad, los partidos políticos, la iglesia y el Estado. Para alcanzar este objetivo, se parte de la hipótesis de que el castigo y la vigilancia al aborto, que se llevaron a cabo en la ciudad por las instituciones judiciales y el derecho penal, pretendieron mantener en funcionamiento los mecanismos de control social y legitimar el poder de las élites políticas en la sociedad.

La hipótesis es desarrollada en tres dimensiones: primero, reconstruye el concepto desde la historiografía; segundo, presenta la tipificación del aborto como delito en los códigos penales y, por último, desvela la estructura judicial y el procedimiento penal que fueron llevados a cabo en estos casos. Estas dimensiones obedecen a tres problemas que orientaron el proceso investigativo. En general, se planteó el problema principal de la siguiente manera: ¿cómo era controlado el aborto en Bucaramanga durante la república liberal? A partir de esta pregunta se plantearon tres problemas específicos que ayudaron a emprender su estudio. Primero, ¿de qué manera han abordado el tema otros autores?; segundo, ¿qué antecedentes legales influyeron en la tipificación del aborto como delito durante la república liberal?; tercero, ¿cuáles fueron las características del procedimiento penal llevado a cabo por los agentes judiciales de la ciudad?

Para responder a los anteriores problemas se tomó como referente la teoría del control social planteada por Foucault en la que se afirma que las relaciones de poder y dominación se encuentran dentro de una ingeniería social que se ejerce a través de las instituciones que fueron creadas para "disciplinar la sociedad" y que a pesar del aparente aislamiento que tienen unas con otras se puede observar una compleja red interdependiente de dominación. Así, a partir de esta perspectiva, es posible capturar desde el inventario de las instancias de poder de la comunidad y el examen de las relaciones existentes cómo funcionan el sistema de justicia y el control social, teniendo en cuenta que el control penal y punitivo no pretendía únicamente controlar si las acciones de los individuos rompían con la ley o no, sino también en mantener un estado de vigilancia sobre sus acciones (Foucault, 1996, p. 44). 
De manera que este estudio pretende desvelar estas relaciones de dominación y control institucional hacia la práctica del aborto; por esta razón, primero, se agrupan las fuentes secundarias que definen el concepto para darle claridad a los objetivos o variables que se van a estudiar; segundo, se hace un recorrido histórico por las legislaciones nacionales que influyeron en el período estudiado y, finalmente, se presenta el procedimiento penal que exigió reunir la documentación pertinente para mostrar cómo actuó la justicia en materia de aborto, cómo se investigaban los hechos y cómo se aplicaron las leyes en el proceso penal. Las fuentes que se utilizaron para construir el proceso penal fueron archivos y publicaciones.

Para abordar la documentación primaria en esta parte de la investigación, se siguieron las técnicas de la hermenéutica y el análisis del discurso, las cuales permitieron examinar de manera cualitativa la información y obtener datos necesarios para crear una imagen histórica del aborto. La hermenéutica, como herramienta metodológica basada en un conocimiento previo de los supuestos históricos y filosóficos de la realidad que se intenta comprender, permite interpretar los procesos de cambio a través del esclarecimiento de la historicidad; este esclarecimiento demanda la comprensión del fenómeno estudiado a partir de la crítica de fuentes (Dilthey, 1999, p. 248). En este punto, el análisis del discurso es indispensable, ya que con esta herramienta se cuestiona sobre el sentido y el contexto de la palabra escrita en su función comunicadora de ideas que pretenda un determinado orden político, económico y social.

\section{El aborto en la historiografía}

La Corte Constitucional colombiana, en el 2006, emitió la sentencia C-355, en la cual se despenalizó el aborto en tres casos: primero, por malformación; segundo, por violación; y tercero, cuando esté en riesgo la vida de la madre o del ser por nacer. Así, el desarrollo jurisprudencial fue soportado por la Constitución Política de 1991 en la defensa de los derechos fundamentales de la mujer. Es decir, en su derecho a la vida y a la prestación de servicios de salud sexual y reproductiva, que le permitan a la mujer decidir sobre la práctica legítima del aborto inducido (Triana, Soto \& Peña 2012).

Esta sentencia fue producto de múltiples debates entre movimientos sociales y académicos, la Iglesia católica y distintas corrientes religiosas, la institución de justicia desde el derecho penal y los partidos políticos. Las discusiones actuales muestran la notable pertinencia del tema como un fenómeno social que toca la sensibilidad política, moral y legal de la sociedad colombiana.

El Estado, en teoría, es concebido como un Estado social, democrático y participativo, respetuoso de la vida y de la dignidad humana, y abierto al pluralismo, 
que debe, por tanto, conectar tres dimensiones en su ejercicio: ser reflejo de una sociedad que admite y promueve la diversidad; aprecia de modo positivo las distintas aspiraciones y valoraciones sociales para proteger la libertad religiosa, de conciencia y pensamiento, así como la libertad de expresión; y establece los cauces jurídicos, políticos y sociales que sirvan para dirimir posibles conflictos que se presenten en momentos determinados: como en los casos de aborto.

No obstante, en la historia del derecho penal en Colombia lo primero que advertimos es la fuerte influencia de la Iglesia católica en su producción. En 1945, Cabanellas condenó moralmente el aborto y lo concibió como un acto criminal, en el cual la inocencia de los "criminales" dependía de sus antecedentes morales y sociales. Por esta razón, se dividió a la mujer en la madre honorable, víctima de repudio social que debía ser absuelta de toda culpa, y la mujer egoísta, merecedora de una sanción penal por olvidarse de sus deberes sagrados y del instinto supremo de la maternidad por entregarse al lujo y a los placeres carnales. Sustentando la idea anterior, Hurst (1998) resaltó que desde los inicios del cristianismo el aborto fue considerado como un acto pecaminoso practicado para ocultar las irregularidades sexuales y el adulterio.

En 1950, Surbled señaló que los médicos consideraban que el aborto solo debía ser permitido al morir el embrión; de lo contrario, debía ser declarado como una peligrosa práctica criminal porque era producida por personas que no estaban capacitadas para llevar a cabo el procedimiento; no obstante, en 1955 Franco propuso que toda práctica abortiva fuera catalogada como homicidio, aun cuando estuviera en peligro la vida de la mujer, ya que su misión más sublime dentro de la raza humana era ser mujer madre que ayudara a multiplicar la especie y procrear.

En contraposición a lo planteado por los anteriores autores, Martínez (1972) consideró que existía la tendencia a confundir las nociones de pecado y delito en materia sexual debido a la repulsión y el odio contra la sexualidad propagados por el cristianismo; por este motivo, expresó que la ley penal no puede castigar todos los pecados, ya que algunos atentaban contra la intimidad del individuo y a esta le correspondían solo las conductas externas que perturbaban el orden social y afectaban la libertad, la dignidad y los derechos de las demás personas.

Por otra parte, a finales del siglo $\mathrm{XX}$, se iniciaron trabajos sobre el aborto dentro de un contexto social; tal es el caso de la investigación realizada por Spicker (2000) en donde se afirma que el aborto fue una forma de resistencia de las mujeres esclavas a la dominación española y a la manera como era utilizado su cuerpo. Igualmente, la historiadora Reyes (1996) señaló que con el proceso de modernización muchas mujeres campesinas emigraron a las ciudades y se dedicaron a las labores domésticas. Estas mujeres, según la autora, despertaron 
en los varones, de la clase media y alta, deseos sexuales que terminaban en embarazos no deseados, y por temor al castigo y a quedarse sin empleo, estas mujeres recurrían al aborto desafiando normas religiosas y legales.

En este sentido, Speckman (1997) cataloga este tipo de mujeres como marginales quienes se apartaron del estereotipo femenino al violar los códigos de conducta socialmente aceptados cometiendo un acto considerado como delictivo. Sin embargo, una de sus conclusiones es que los comportamientos delictivos eran utilizados por las clases dominantes para justificar su superioridad moral sobre los dominados y con ello legitimar el dominio político debido a que estos no estaban relacionados directamente con el individuo sino con un grupo socioeconómico determinado.

Luego de dictarse la sentencia C-355 de 2006 por la corte constitucional colombiana, los posteriores estudios sobre el aborto se polarizaron en dos posturas enfrentadas: por un lado, estaban quienes consideraban que la mujer tenía derecho a decidir sobre su cuerpo; y por otro, los que pedían protección jurídica a la vida del feto considerándolo como una persona con derechos e intereses (Triana, Soto \& Peña 2012). Dentro de esta primera perspectiva encontramos a Molina (2006), quien consideró que las inadecuadas condiciones en las cuales se practicaba el aborto clandestino afectaban psicológica y físicamente a las mujeres, y, en consecuencia, se presentaban miles de muertes. Según este autor, el Estado a través del derecho penal mantuvo el control sobre las conductas privadas femeninas para que prevaleciera la imagen de la mujer como modelo maternal. En consecuencia, el aborto fue considerado como un homicidio que merecía un castigo con fines preventivos para que no fuera repetida dicha conducta.

Ahora bien, Abadía (2006) realizó un paralelo entre los intereses del pensamiento liberal al crear un Estado laico que, por un lado, garantizara la coexistencia entre ciudadanos apartando la moral de la ley, y por otro lado, su estructura de pensamiento que mantuviera una dualidad contradictoria al considerar de mayor jerarquía lo masculino, mientras lo femenino era negativo e inferior. Esta dualidad generó consecuencias trascendentales en la evolución del pensamiento penal y no permitió avances en torno a la separación entre derecho y moral. Por tal motivo, durante la república liberal no se eliminaron los vestigios de carácter religioso en el derecho penal; al contrario, la doctrina católica siguió influyendo en las legislaciones laicas, y la atenuación de algunas penas otorgadas por los códigos penales fue producto de ideas morales y religiosas impuestas por la iglesia.

De la misma manera se expresa Betancur (2006) al respecto, ya que considera que la legislación penal de 1936 se rigió, al igual que la de 1890, por principios 
morales en oposición al aborto y era reflejo de una sociedad que no le otorgaba ningún valor a la mujer como ser individual capaz de afrontar su sexualidad. A manera de ejemplo, se presentan las conclusiones de Gutiérrez (2009) quien consideró que la sexualidad femenina estuvo relacionada con los códigos sociales de honor. Por tal motivo, las nociones sobre la moral sexual femenina eran de gran importancia para el Estado y para la sociedad: el honor evaluaba la gravedad y el tipo de delito cuando una mujer se deshacía de su hijo legítimo, ya fuera por aborto o por infanticidio. Estas conductas fueron controladas y perseguidas, y su comprobación dependía de la conjetura de los vecinos fundamentada en el rumor público y en el chisme, debido a que eran pocos los conocimientos ginecológicos y obstétricos con los que contaba la justicia penal.

Por último, del Valle y Hernández (2010) consideraron que, aunque los dictámenes periciales fueron objetados por falta de cientificidad en las decisiones judiciales, la moral no fue determinante, ya que los funcionarios atendieron las exigencias probatorias en los términos de las reglas que regían el enjuiciamiento criminal; también exigieron demostrar los elementos de la conducta criminal y atendieron las circunstancias agravantes y atenuantes consagradas en el Código Penal.

\section{El aborto en la legislación nacional}

La legislación nacional sobre el aborto hizo parte del proceso de transformación del derecho penal en Colombia que se llevó a cabo principalmente por la recepción de tendencias y teorías tomadas de legislaciones extranjeras. Estas teorías no fueron un resultado de procesos de investigación en materia penal sino un intento de adaptarlas al contexto nacional y a sus realidades locales (Gómez, 2006). De manera que en este apartado se presentan los antecedentes de las leyes que regían sobre aborto en el período estudiado.

En primer lugar, encontramos las Siete Partidas del siglo XIII que se mantuvieron vigentes en la Nueva Granada durante buena parte del siglo XIX. Esta legislación estableció el poder de la Iglesia católica sobre los hombres y las cosas, otorgando a las Siete Partidas el fin de ordenar la vida social de los hombres siguiendo los mandamientos divinos ${ }^{1}$. En ellas, el matrimonio tenía como objetivo "hacer hijos y crecer el linaje de los hombres", así como alejar a los hombres del pecado de la fornicación y del placer de la carne y reglamentar su sexualidad. Sin embargo, el aborto no era considerado como delito, a menos que se presentara la muerte de la mujer; al delincuente se le imponía la pena menor de destierro por cinco años a una isla sin tomarle sus bienes ${ }^{2}$.

\footnotetext{
1 Las siete partidas, del rey don Alfonso, El Sabio, Madrid, Imprenta Real, 1808, Primera partida, p. 2.

2 Séptima partida, p. 118.
} 
Luego en 1837 al redactarse el primer Código Penal del país se buscaba independizar el nuevo Estado republicano de las concepciones del orden jurídico heredado de la Colonia, aunque esta pretensión no se llevó a cabo porque las élites políticas se aferraron a las ideas coloniales como único recurso para poder formar una sociedad que concentrara y estabilizara el nuevo poder estatal (Peñas, 2006, p. 13).

El delito ${ }^{3}$ se definió combinando dos corrientes filosóficas del derecho penal: la teoría del delito de la dirección volitiva del autor, que sanciona las conductas por su intención de causar daño y la teoría legalista, tomada del Código Penal francés, según la cual el hecho ilícito penal se caracterizaba por ser una infracción de lo que la ley dice que es delito. Así, las penas se definieron con el fin de reestablecer el orden social que el delito cometido había perturbado; también para retribuir el daño causado por el delincuente a la víctima y a la sociedad, e infundir temor para disuadir a quienes estuvieran tentados a cometer delitos similares.

De manera que las leyes que definieron el aborto en esta legislación fueron muy severas castigando con el destierro, el presidio y los trabajos forzados a quienes procuraran el aborto a una mujer, aunque no hubieran tenido resultados. A los médicos, boticarios, cirujanos, comadronas o parteras que estuvieran relacionados con el aborto o facilitaban los medios se les imponían los anteriores castigos y se les inhabilitaba su profesión de manera perpetua, aunque si actuaban para salvar la vida de la mujer no incurrían en ninguna pena. A las mujeres que empleaban o consentían los medios para el aborto se les sancionaba con el presidio de seis a doce años si el aborto resultaba; en caso contrario, de cinco a diez. Sin embargo, las mujeres honradas y que contaran con buena fama eran recluidas de uno a cuatro años, de la misma manera que las personas que provocaban el aborto sin ninguna intención.

Ahora bien, con el liberalismo radical que estuvo influenciado en materia penal por la corriente ilustrada y la escuela clásica italiana, las penas se humanizaron y fueron menos severas para que se adecuaran a las ideas del proyecto liberal radical. Por esta razón, las penas por aborto en el Código Penal de 1873 fueron más flexibles. Por un lado, a quienes intentaban causar el aborto a una mujer embarazada sin su consentimiento se les imponía una pena de reclusión o presidio de seis meses; si contaban con el consentimiento de la mujer, la pena era de tres meses; y si el aborto resultaba en la muerte del feto la pena era de un año. Por otro lado, los médicos, cirujanos, boticarios o parteras eran condenados

$3 \quad$ El delito en el artículo 1. ${ }^{\circ}$ de este código fue definido como: "la voluntaria y maliciosa violación de la ley por la cual se incurría en alguna pena". En Recopilación de leyes de la Nueva Granada, Código penal de 1837, Bogotá, 1845, Libro primero, De los delitos y de las penas en general, Titulo primero, Disposiciones preliminares, artículo 1, p. 425. 
por un año y desterrados de dos a seis años con inhabilitación por cinco años para ejercer su profesión, de la misma manera que en la legislación anterior; quienes actuaban para salvar la vida de la mujer no incurrían en pena alguna. Finalmente, los códigos de honor se mantuvieron vigentes en la legislación de 1873, con la diferencia de que si a la "mujer honrada" no le resultaba el aborto no era penalizada, pero si el aborto ocurría la mujer era arrestada de cuatro a seis meses. Por el contrario, si el honor de la mujer no era demostrado se recluían por seis meses, si el aborto no resultaba, y por un año, si tenía resultado ${ }^{4}$.

Años más tarde, en 1890 durante el período de la Regeneración se aprobó un nuevo Código Penal que buscaba rescatar las tradiciones hispanas, establecer el unitarismo y fortalecer la unión del Estado con la Iglesia católica. En este período resurgió el movimiento político conservador creado por Rafael Núñez con el fin de oponerse a los planteamientos sobre el Estado de los liberales radicales. Si una persona causaba el aborto de una mujer sin su consentimiento, incurría en una pena de cinco a diez años de presidio, y con su consentimiento, era de cuatro a ocho años ${ }^{5}$. A quienes ejercían la medicina se les aplicaban las anteriores penas con un aumento de seis meses a un año, de la misma manera que en las anteriores legislaciones; si se llevaba a cabo para salvar la vida de la mujer se redimía de la pena ${ }^{6}$.

Las "mujeres honradas" que actuaban para encubrir su fragilidad eran llevadas a prisión de tres a seis meses si no se verificaba el aborto, y de cinco a diez meses si era verificado. Si las mujeres no eran consideradas "honradas" debían ser recluidas de uno a tres años si el aborto resultaba; en caso contrario, de seis meses a un año. Asimismo, las personas que sin intención causaran el aborto a una mujer debían ser recluidas por uno a cuatro años; esta ley se mantuvo vigente desde el Código Penal de 1837.

4 Código penal de los Estados Unidos de Colombia (ley 112 de 26 de junio de 1873), Bogotá, Imprenta de Medardo Rivas, Título segundo, División y clasificación de los delitos, Artículos 488-491, p. 74-75.

5 El condenado a la pena de presidio era conducido al establecimiento respectivo, y se le obligaba a trabajar en las obras que designara la autoridad política, por nueve horas diarias por lo menos, salvo impedimento físico. Cuando la pena no excedía de seis meses se podía cumplir en la cárcel y no llevaba prisión; si el tiempo que debía permanecer en el establecimiento era menor de cinco años, debía llevar grillete al pie, y si pasaba de cinco años llevaba grillete y cadena. Las personas mayores de sesenta años, los menores de dieciocho, las mujeres y los ministros del culto sufrían la pena de presidio en los establecimientos de reclusión; los que cumplían 60 años estando en el presidio, pasaban a reclusión; esta pena no podía excederse de veinte años. En (Código Penal colombiano de 1890, 1910. p. 5.)

6 La aprobación de la práctica del aborto terapéutico para salvar la vida de la mujer tenía esta aclaración: "no por eso debe creerse que la ley aconseja el empleo de esos medios, que generalmente son condenados por la Iglesia. Únicamente se limita eximir de pena al que con rectitud y pureza de intenciones se cree autorizado para ocurrir a dichos medios" que se ajustaba a los ideales del Estado conservador y sus lazos con la Iglesia católica. 
Finalmente, con la llegada al poder de los liberales en 1930, se expidió un nuevo Código Penal que significó el inicio de una transformación política y social del país. Durante la república liberal el país se encontraba en un proceso modernizador tanto en el campo como en la ciudad producto de la bonanza cafetera y del surgimiento de la industria que produjo la movilización de la población rural a los pueblos más grandes y a las ciudades. El crecimiento poblacional de las ciudades estuvo acompañado por las ideas políticas que la élite partidista promovió en las diferentes regiones del país. La nueva ideología partidista atacó todo tipo de restricciones a la libertad individual y todo privilegio arraigado, promoviendo un programa social igualitario argumentado a partir de premisas racionales y utilitarias (Henderson 2006, p. 130).

Sin embargo, durante las décadas de 1930 y 1940 la sociedad y la cultura fluctuaron entre los mundos de la tradición y del cambio ya que se aferraron a actitudes arraigadas llenas de prejuicios y de estereotipos sexuales, dentro de los cuales estaban las ideas relativas a las mujeres. Según Luna y Villarreal (1994), en la ideología liberal del siglo XX existió una incoherencia porque los derechos de las mujeres no se fundamentaron en una visión de ellas como sujetos de derechos políticos sino que prevaleció su innovación como madres reproductoras.

El Código Penal de 1936 se basó en los principios de la Escuela positivista italiana que consideraba que la razón de ser de la justicia penal era defender la sociedad y tratar al delincuente como un ser anormal que pertenecía a una minoría desviada en el momento en que violaba la ley penal. De manera que, los legisladores durante este período consideraron que el derecho penal debía funcionar con el fin de prevenir el crimen, la pena era preventiva a cambio de la retribución sostenida, en tanto que la misma no solamente debía retribuir, sino que, además, era necesario resocializar al delincuente.

En esta legislación el delito era comprendido como un fenómeno natural, producido por el medio social en que se desarrollaba el hombre que lo cometía. La causa del fenómeno delictivo se debía a factores antropológicos, físicos, geográficos o sociales. Por ello, se tuvieron en cuenta las circunstancias de mayor o menor peligrosidad para sancionar al delincuente, según la gravedad y modalidades del hecho delictivo, los motivos determinantes y la personalidad del agente del delito (Ortega, 1937).

Específicamente, el aborto fue un delito contra la vida y la integridad personal y, a diferencia de las anteriores legislaciones, el aborto terapéutico no fue legal y algunas de las penas fueron más duras en comparación con el Código Penal de 1890. Por ejemplo, se estableció la pena de prisión de uno a cuatro años, para quien procurara el aborto a una mujer con su consentimiento, y para la 
mujer embarazada que se causara el aborto o permitiera que otra persona se lo causara. Quienes causaran el aborto sin consentimiento de la mujer incurrían en prisión de uno a seis años7; si ocasionaba la muerte de la mujer se aplicaba lo dispuesto en el artículo $367^{8}$. Además, la pena aumentaba hasta en la tercera parte e imponía la suspensión del ejercicio de la profesión por dos meses a seis años a los médicos, cirujanos, farmaceutas o parteras que hayan sido responsables del aborto, aunque se disminuía la sanción de la mitad a las dos terceras partes o se le concedía el perdón judicial a las mujeres que hayan causado el aborto para salvar el honor ${ }^{9}$.

\section{El ahorto en Bucaramanga 1930-1946}

A lo largo del período estudiado, la ciudad experimentó un proceso de transformación urbana, económica y social que la situó como el centro comercial e industrial más importante del oriente colombiano, que atrajo un gran número de población campesina en busca de "mejores oportunidades". Una de las industrias que aportó en la transformación del modo de vida bumangués fue la industria tabacalera que creó nuevas relaciones de trabajo y configuró el fenómeno social llamado "trabajo a domicilio", que ubicaba el centro laboral dentro del hogar. En el año 1944 existieron pequeños talleres o industrias clandestinas que ofrecían muy bajos salarios y pobres condiciones laborales a los trabajadores que, en su mayoría, eran mujeres dedicadas a la fabricación del tabaco y del cigarro como rolleras y torcedoras; estas mujeres solo recibían el 2 \% de la utilidad por elaborar el producto y eran las encargadas de orientar a los niños para que aprendieran a trabajar y sobrevivir de la misma manera (Valdivieso, 1992, p. 46).

También, en la ciudad existieron proyectos de sala-cuna en donde las obreras dejaban sus hijos al cuidado de las niñeras de turno. En uno de estos lugares según lo cuenta Rúgeles en 1933 hubo un allanamiento por una denuncia que culpaba a una mujer del servicio de echar una criatura que parió al excusado.

$7 \quad$ Art. 47. La pena de prisión se cumplía en un establecimiento destinado al efecto, o en una colonia agrícola especial; los condenados a ella no estaban obligados a trabajar fuera del respectivo establecimiento (Ortega, 1937, p. 92).

8 Artículo 367. El que eficazmente induzca a otro al suicidio estará sujeto a la pena de tres meses a dos años de arresto. Cuando el agente haya procedido por motivos innobles o antisociales, se duplicará la pena (Ortega 1937, p. 263).

$9 \quad$ "El perdón judicial es una gracia de carácter excepcional, que implica especiales condiciones para ser acreedor a ella. No solo requiere una situación jurídica carente en absoluto de circunstancias de mayor peligrosidad, sino, aún más, que las modalidades especiales del hecho demuestren la carencia absoluta de peligrosidad del responsable. Se trata de un problema en cuya determinación entran en mucho, no solo las comprobaciones procesales, sino el concepto que se forme el juzgador acerca de la personalidad de quien va a disfrutar de aquella gracia, de sus particularidades psíquicas, teniendo que hacer un verdadero pronóstico consistente en la previsión del futuro comportamiento criminal del sujeto favorecido con tal beneficio" (Sentencia, 2 febrero 1951, LXIX, 161) (Ortega 1937, 107) 
Se rompió para investigar, entraron con lámparas eléctricas y no encontraron nada. La mujer se declaró inocente y los investigadores observaron que no se encontraba enferma ${ }^{10}$.

Otra industria que influyó en la transformación social de la ciudad fueron las obras públicas que demandaron mano de obra de poblaciones aledañas y trajeron la transformación urbanística de la ciudad. Paralelamente, la nueva configuración urbana entre 1930 y 1946, dio paso al establecimiento de una diferenciación social que destinó nuevos espacios de carácter socio-cultural a sus habitantes (Álvarez y Ramírez, 2013, p. 41).

Dentro de este contexto socioeconómico, la ciudad fue aumentando su número poblacional y, con ello, sus problemas sociales, sus conflictos y sus crímenes. Por esta razón, según Álvarez (2012) en Bucaramanga la élite y las autoridades locales, establecieron medidas y mecanismos de control social con el fin de regular las relaciones sociales y el comportamiento de los individuos. Uno de estos mecanismos fue la consolidación del poder judicial que se encontraba organizado de la siguiente manera: en primer lugar, estaba la Corte Suprema de Justicia; luego, los tribunales superiores del Distrito Judicial; le seguían los jueces superiores y de circuito y a estos, los jueces municipales, y finalmente, los jueces de menores ${ }^{11}$.

Podemos observar que algunos ciudadanos por miedo al castigo de la ley se vieron obligados a denunciar los hechos. Así nos muestra uno de los trámites por aborto en donde uno de los testigos expresó que lo que sabía era solo porque otra persona se lo había contado. Sin embargo, una vez se supo la noticia de lo que había pasado se resolvió formular el denuncio correspondiente para no correr con alguna responsabilidad ${ }^{12}$.

A los juzgados superiores les correspondía conocer el delito de aborto, y sus jueces tenían como función instruir los sumarios para averiguación de los delitos, y podían comisionar a los funcionarios de policía o a los judiciales de igual o inferior rango. La estadística de los asuntos criminales se llevaba a cabo teniendo en cuenta los siguientes datos:

10 Diarios de Bartolomé Rúgeles. Tomo 73. 1933

11 Leyes expedidas por el Congreso Nacional en su legislatura del año de 1931. Sesiones ordinarias. Bogotá: Imprenta Nacional, 1931. Ley 105 de 1931. 17 de octubre. Sobre organización judicial y procedimiento civil. Art. 1. p. 19.

12 Centro de Documentación Histórico Regional-Universidad Industrial de Santander, Archivo Histórico Judicial de Bucaramanga (en adelante: CDHIR-AHJB), Penal Homicidios, Caja 152, Expediente 2619, f. 6. Énfasis agregado. 
[...] calificación del delito conforme al tecnicismo de la ley penal; edad, sexo y ocupación habitual del delincuente, causa o móvil del delito, pruebas con las cuales se acredite el hecho criminoso, expresión de si el reo es o no reincidente, clima del lugar en donde el delito se haya consumado, pena impuesta, duración del proceso ${ }^{13}$.

Los juzgados del circuito eran los encargados en segunda instancia de investigar los delitos en sus respectivas jurisdicciones con carácter de jueces de investigación; estos estaban por debajo de los Juzgados Superiores del Distrito Judicial. El circuito judicial de Bucaramanga contaba con cuatro juzgados y no solo extendió su jurisdicción al área urbana, sino que abarcó otros municipios y otras poblaciones, con sus respectivos corregimientos, fracciones y caseríos. Podemos observar que para este periodo en la ciudad se habían instalado todos los componentes del sistema penal por ser capital del departamento de Santander y se concentraron las actividades y diligencias pertinentes a la Administración de Justicia sin la necesidad de recurrir a una instancia o jurisdicción de mayor importancia ${ }^{14}$.

Los funcionarios judiciales iniciaban las investigaciones basándose en los principios del Código de Procedimiento Penal con un sumario que reuniera todas las actividades para comprobar el cuerpo del delito; en él se basaban los jueces de los juzgados y los fiscales para emitir concepto sobre la acción penal y dictar sentencia. El fin de estos sumarios era conocer la personalidad de los delincuentes y vigilar las conductas del cuerpo social para así determinar si sus acciones merecían ser calificadas como delictivas o no y valorar los perjuicios que ocasionaron con la infracción y eran iniciados cuando los funcionarios se enteraban personalmente de los casos, por una denuncia, por avisos confidenciales, por notoriedad pública o por otro medio de alguna infracción penal que debía ser investigada (Ortega, 1937, p. 552).

Por ejemplo, el 2 de noviembre de 1931 uno de los detectives de la inspección de permanencia de la policía departamental encontró en el pasaje Porras un feto de cuatro meses de concebido y al suponer que se trataba de un delito informó al jefe de la inspección para que se empezara la investigación correspondiente ${ }^{15}$.

En otro caso del 20 de junio de 1943 se inició un trámite judicial con una carta que llegó al Departamento de Higiene de la ciudad por un remitente desconocido. En esta, se denunció que en la botica de Milton G. se había operado a una mujer con el fin de hacerla abortar; la principal razón, según su escritor fue dar conocer los hechos para que se castigara a los hombres que hacían dinero prestándose

13 Revista judicial de Bucaramanga. Órgano del tribunal superior, Bucaramanga: Imprenta del Departamento, diciembre 31 de 1935, Art. 103, p. 42.

14 Revista judicial de Bucaramanga. Órgano del Tribunal Superior, Bucaramanga: Imprenta del Departamento, 31 de marzo de 1932, p. 339.

15 CDHIR- AHJB, Penal Homicidios, Caja 152, Expediente 1555, f. 1. 
para casos que la moral y la naturaleza prohíben ${ }^{16}$. Los oficiales determinaron que existía un indicio de que se había cometido un hecho criminal que merecía ser castigado e iniciaron el sumario correspondiente.

Cuando se presentaban denuncias los ciudadanos se acercaban a la inspección de policía o a la alcaldía de la ciudad. En el transcurso de 1930-1944 encontramos seis denuncias por aborto. Una de ellas fue notificada el 10 de julio de 1935 por Crisanto M. quien denunció que unos agentes de la policía llegaron a su casa causando alboroto y obligando a Elia M de L., que se encontraba en estado de embarazo, a que les abriera la puerta; por el susto y la impresión que recibió esta mujer abortó. El denunciante ratificó que las autoridades estaban obligadas a velar por la vida de los nacidos y por nacer, ya que desde la concepción se nace con un mismo derecho ${ }^{17}$.

La segunda fue anunciada por Carmen V. el 19 de febrero de 1940 contra una comadrona por haberle provocado el aborto sin su consentimiento al convencerla que se dejara realizar un lavado estando en estado de embarazo. Después del lavado, se sintió enferma hasta que se presentó el aborto. ${ }^{18}$

La tercera denuncia aparece el 4 de diciembre de 1942, por Griselda M. dedicada a los oficios domésticos contra Isabel M. y Adela R. por dos abortos provocados. La denunciante confesó que por ser amiga e inquilina de Isabel M. podía detallar minuciosamente los hechos ocurridos. Denunció que su amiga estuvo embarazada en dos ocasiones y que para que su "querido" no se diera cuenta de su estado hizo que Adela R. le aplicara inyecciones para abortar.

La denuncia contenía detalles que confirman que dentro de la sociedad algunos individuos tenían conocimiento de las personas que practicaban abortos, cuánto cobraban, qué herramientas utilizaban y cuáles eran las consecuencias de su práctica ya sea legal, moral o médica. En este caso se denuncia que los abortos fueron provocados por una comadrona y se relató que:

[...] Adela R. la llamó a la alcoba y yo me quedé en la sala, yo entré a la alcoba luego con un caldo con huevo y chocolate para Isabel M.; cuando entré pude ver que la tenía acostada en la cama con las piernas abiertas y boca arriba y le tenía puesto en medio de las piernas un aparato el cual le iba metiendo poco a poco y le puso una inyección que yo no sé de qué sería. Al día siguiente Adela R. llegó a la casa de Isabel M. y la volvió a acostar en la misma posición y le puso otra inyección a las ocho de la mañana y así permaneció hasta la tarde y a las seis le quitó los aparatos y se fue de la casa. A las dos de la mañana abortó y sentándose en el vaso de noche arrojó una criatura que

\footnotetext{
CDHIR-AHJB, Penal Homicidios, Caja 109, Expediente 1964, f. 3.

CDHIR-AHJB, Penal Homicidios, Caja 27, Expediente 555, f. 1.

CDHIR-AHJB, Penal Homicidios, Caja 83, Expediente 1549, f. 1.
} 
era varón y después de que pasó esto se hizo el aseo ella misma se fue al excusado y arrojó allí todo. Al año siguiente quedó embarazada otra vez y llamó a Adela R. para que le hiciera el mismo trabajo y a los tres días se presentó el aborto y Adela R. misma me mostró la criatura que era una hembrita y ella misma fue y la enterró en el solar de la casa debajo del lavadero, al decirle que se había convertido en una llorona le propuso a Adela R. llevar la criatura al cementerio y Adela R. dijo que eso no era posible pues podían descubrirlo y eso era grave. Este asunto le costó sesenta pesos ${ }^{19}$

En la cuarta denuncia presentada el nueve de julio de 1944 se pudo evidenciar que las empleadas domésticas estuvieron en constante vigilancia por sus patrones, compañeras de trabajo o por sus vecinos debido a que atendían a cualquier cambio que ocurriera en los cuerpos de estas mujeres. En esta denuncia, Cecilia M., patrona de la sindicada, relató que se había enterado por sus empleadas que una de ellas (Isabel G.) había presentado dolores de estómago y anteriormente le había pedido treinta centavos para comprarse unas píldoras que le produjeron el aborto del cual se enteraron porque el feto fue encontrado en el patio vecino. Cecilia M. llevó a Isabel G. a donde se encontraba el feto para que dijera lo que había pasado, pero esta se puso a llorar y Cecilia M. le ordenó que recogiera el feto y que se fuera para el hospital. ${ }^{20}$

En otro caso, podemos observar que no solamente las empleadas domésticas estuvieron en el punto de mira de la sociedad sino también aquellas que eran abandonadas por sus maridos, como es el caso de Beatriz H., a la que acusaron de haber abortado presa por la miseria, porque después del abandono de su marido estaba más flaca y ya no se le notaba estómago ${ }^{21}$.

La última denuncia fue presentada por Raúl G., un obrero de una fábrica tabacalera, el doce de agosto de 1944 contra María M. por haber hecho abortar a su hija Carmen M. En su denuncia informó que Carmen M. se encontraba en estado de gravedad como consecuencia del aborto que la madre le hizo provocar con remedios porque no quería que su hija tuviera hijos ${ }^{22}$.

Luego de recibir estas denuncias los funcionarios judiciales procedían a investigar los hechos y comprobar el delito, y sus perjuicios para la sociedad. Las investigaciones iniciaban después de dictarse el documento cabeza de proceso y, luego, los funcionarios iban acompañados de testigos o peritos al lugar del delito para examinar los rastros y recoger los elementos que pudieran esclarecer los hechos (Ortega 1937, 563). En las investigaciones se tenía en cuenta si realmente se había infringido la ley penal; quién o quiénes fueron autores o partícipes de la infracción; cuáles fueron los motivos que influyeron

\footnotetext{
19 CDHIR-AHJB, Penal Homicidios, Caja 83, Expediente 1545, f. 1-2.

20 CDHIR-AHJB, Penal Homicidios, Caja 83, Expediente 1544, f. 3.

21 CDHIR-AHJB, Penal Homicidios, Caja 152, Expediente 2619, f. 1.

22 CDHIR-AHJB, Penal Homicidios, Caja 83, Expediente 1553, f. 1.
} 
en la violación de la ley penal; en qué circunstancias se realizó la infracción; las características de la personalidad del procesado; su conducta anterior; sus condiciones de vida individual, familiar y social, y los daños y perjuicios de orden moral y material que la infracción había causado. Para sustentar las investigaciones, eran llamados a declarar los testigos para interrogarles sobre los autores de la infracción, su participación en los hechos; antecedentes y conducta posterior al delito del sindicado.

En algunos casos, en sus testimonios reconocían que se habían enterado por otras personas sobre lo ocurrido. Como, por ejemplo, en el caso donde se había acusado a agentes de la policía de haber causado el aborto de Elia M de L. uno de los testigos declaró que se había enterado de lo ocurrido porque su esposa le había contado y que esta se había enterado por el mismo denunciante ${ }^{23}$. Al final los sindicados se declararon inocentes y el dictamen de medicina legal determinó que la causa del aborto de Elia M. de L. no fue por ninguna impresión nerviosa, susto o choque psíquico, y esta mujer murió en el hospital sin conocerse las causas de la defunción.

Cuando un sumario iniciaba contra desconocidos, los investigadores tuvieron dificultades para poder comprobar los elementos de la infracción porque no contaban con instrumentos científicos y las pruebas eran distorsionadas a causa del entorno. Por ejemplo, el dos de noviembre de 1931 fue encontrado un feto por un detective de la ciudad quien inició la denuncia con el fin de descartar o comprobar algún hecho criminal. Los peritos realizaron una inspección ocular para que se mostraran rastros o señales dejadas por la infracción como instrumentos o cualquier objeto que hubiera podido servir para cometer el delito. Sin embargo, no pudieron certificar si el feto había nacido vivo o muerto ni tampoco se pudieron tomar las huellas digitales de la persona que dejó huellas de sangre por falta de aparatos científicos y por la humedad del piso. ${ }^{24}$

Cuando los testigos señalaban a presuntos culpables de cometer el delito, eran llamados a indagatoria para conocer la verdad sobre los hechos y la versión de los imputados. Como es el caso de Carmen R. una cigarrera de dieciocho años de edad quien confesó que había abortado con cuatro meses de embarazo después de tener fuertes dolores de estómago y una hemorragia vaginal y que su madre la había ayudado a aliviar los dolores. ${ }^{25}$

La madre relató que su hija la había llamado porque sintió mojada la cama; ella se acercó y notó que tenía una hemorragia; como anteriormente había sido comadrona, la sobó con chicote para que se le pasara el dolor y la hemorragia.

CDHIR-AHJB, Penal Homicidios, Caja 27, Expediente 555, f. 9-10.

24 CDHIR-AHJB, Penal Homicidios, Caja 83, Expediente 1555, f. 2.

25 CDHIR-AHJB, Penal Homicidios, Caja 83, Expediente 1553, f. 5. 
Esta sindicada afirmó que el motivo de la denuncia había sido por venganza porque ella le había puesto un denuncio a Raúl G. por estupro y le había dicho que tenía que casarse con su hija por haberla dejado embarazada. También se llamó a testificar a su abuela que estuvo en el momento de los hechos y participó en el entierro del feto y quien en su declaración expresó que el feto fue guardado en alcohol y enterrado ${ }^{26}$. Por último, se recurrió al dictamen de medicina legal luego de que se examinara al feto y a la madre, para saber la edad del feto, si presentó lesiones de naturaleza criminal y para conocer el día o mes aproximado en que tuvo lugar el aborto en el cual no se encontró ninguna huella de las causas del aborto ${ }^{27}$.

En Carmen R. encontraron que presentaba al tacto vaginal y a la inspección directa del cuello uterino signos que hacían sospechar la ocurrencia del aborto; el principal fue la existencia de una hemorragia por el orificio cervical de la matriz. Aunque medicina-legal no encontró huellas traumáticas, de cortaduras o de cualquier maniobra abortiva en la sindicada, no se descartó la acción criminal, y se explicó que solo con la investigación de los hechos se podría saber el motivo real del delito y aclarar el caso. Por tal motivo, se recomendó examinar el domicilio de las sindicadas para buscar sustancias reputadas como abortivas o cualquier instrumento que pudiera servir para tal hecho. Según el médico legista, la "gente del pueblo" empleaba con frecuencia diversos instrumentos más o menos adecuados que pueden no dejar ninguna clase de huella en el organismo de la madre y del embrión. Estas sustancias e instrumentos eran:

[...] la ruda, salvia, altamisa, ajenjo, marrubio blanco, purgantes drásticos, la hoja de apio etc. o drogas como el plomo, sulfuros, cornezuelo, ergotina, apiol, quinina, mercurio, yodo. También podría ser un indicio la presencia de cánulas especiales, sondas metálicas o de caucho. $O$ diversos instrumentos como varillas de paraguas o de corsé, alambres, baquetas metálicas o de madera, ganchos, agujas de bordado, lápices, plumeros, plumas de ganso o de cualquiera otra ave, varillas de hueso, etc. ${ }^{28}$.

En el caso de Isabel G., esta declara que fue a donde el boticario porque no le había llegado el período y porque sentía muchos dolores y que le dio unas píldoras y le dijo que volviera para que se tomara un purgante que le produjo trastorno ${ }^{29}$.

Esta mujer tenía dieciocho años, declaró que era analfabeta y que se había fugado del municipio de Sativa-Boyacá a Bucaramanga en compañía de una amiga para desempeñarse como empleada doméstica. A la sindicada se le preguntó sobre su pasado sexual y respondió a ello diciendo que había tenido

\footnotetext{
26 CDHIR-AHJB, Penal Homicidios, Caja 83, Expediente 1553, f. 8.

27 CDHIR-AHJB, Penal Homicidios, Caja 83, Expediente 1553, f. 11.

28 CDHIR-AHJB, Penal Homicidios, Caja 83, Expediente 1553, f. 12

29 CDHIR-AHJB, Penal Homicidios, Caja 83, Expediente 1544, f. 2.
} 
relaciones sexuales con un hombre desconocido que le hizo propuestas y que la llevó a una pensión cuando la mandaron al centro a hacer un mandado. Ella no le dio mucha importancia porque ya había sido "deshonrada" en Sativa por el hijo de los patrones donde estaba trabajando. Por esa razón, desconocía su estado de embarazo porque no sentía ningún malestar y fue a donde el boticario solo por un mal de estómago, este fue su relató:

[...] hace ocho días me dio unas gotas en un vaso de agua, y me dio un purgante el miércoles en la noche, eran nueve píldoras de color carmelito, me las tomé allá en la botica y me dio un vaso de agua salada y me dijo que eso era purga y que no fuera a comer nada. Me cobró seis pesos. El jueves sentí muchos dolores y desaliento y me fui para el excusado y allá vi que estaba dando a luz y salió una criatura que estaba muerta y luego vi que estaba prendida de un cordón y lo tiré y salió una cosa gruesa de color rojo y boté todo para el solar vecino. La Sra. Cecilia fue con María y me preguntaron que me pasaba, pero yo no les quise contar, deseaba ocultarles, pero ya la criatura la había botado y me habían pasado los dolores ${ }^{30}$.

En el reconocimiento de medicina legal no se pudo determinar la posible causa del aborto, pero, de acuerdo con el relato de la mujer, se supuso que había sido por el purgante que había tomado, y se explica que existían personas predispuestas y no predispuestas al aborto: en las primeras se puede producir un aborto por acción de purgantes, traumatismos físicos o morales, enfermedades intercurrentes o viajes en vehículos de tracción motora, y en las segundas no se produce por ninguna de estas causas a no ser que sobrepase cierto límite de dosis, ya que si se extrema habría una intoxicación que sería la que produciría el aborto y graves perturbaciones en la salud de la madre. Según el médico legista, existían otras prácticas de laboratorio que eran útiles para hallar la posible causa constitucional o patológicamente adquirida como una sero-reacción de Wasserman u otras, pero que la oficina no contaba con las posibilidades de auxiliarse de tales exámenes; por esta razón "tiene que contentarse con dictámenes extraídos del solo examen clínico"31.

Estos sumarios fueron remitidos a los jueces del circuito penal quienes luego de recibir el proceso lo estudiaban para saber a quién correspondía su conocimiento y ordenaban enviarlo inmediatamente al juez o tribunal competente. Los delitos de aborto fueron estudiados por los jueces superiores del distrito judicial, quienes revisaban el sumario y si encontraban incompleta la investigación o si no se habían practicado algunas diligencias importantes, ordenaban ampliarlo, señalando los puntos concretos de la ampliación. Si la investigación estaba completa, la declaraban cerrada o si se trataba de asuntos cuyo conocimiento correspondía a los juzgados o tribunales superiores, ordenaban pasar el proceso en traslado al respectivo agente del Ministerio Público.

\footnotetext{
30 CDHIR-AHJB, Penal Homicidios, Caja 83, Expediente 1544, f. 4-5.

31 CDHIR-AHJB, Penal Homicidios, Caja 83, Expediente 1544, f. 9. 
Cuando las investigaciones eran ampliadas por los funcionarios de instrucción, se las devolvían al juez para que la declarara cerrada o la remitiera al respectivo Agente del Ministerio, que estudiaba el expediente y emitía su concepto basado en los hechos demostrados en que pedía el enjuiciamiento o el sobreseimiento del procesado.

Cuando los jueces no consideraron que fuera el caso de manifestar auto de proceder, dictaban un auto de sobreseimiento definitivo que consistía en la inocencia del procesado y en que el hecho que dio lugar a la investigación no era constitutivo de delito. En el caso en que se acusa a Víctor S. de el haberle causado el aborto a Elia M de L. no fue posible establecer el cuerpo del delito; por ello se dedujo sobreseer definitivamente el proceso a favor de los sindicados y se solicitó que fuera confirmado por el Tribunal Superior de Bucaramanga. El tribunal confirmó el sobreseimiento definitivo por no haber sido hallada la partida de defunción y por no existir el cuerpo del delito, pues el dictamen médico-legal dedujo que no hubo causa externa que hubiera producido el aborto ${ }^{32}$.

A Beatriz H. se le resuelve su caso con un sobreseimiento definitivo ya que según el juez las apreciaciones del denunciante fueron equivocadas y sufrió "tremenda ilusión al dar por verídico un posible embarazo fantasma en su inquilina" 33 .

Otro sumario que se califica con el sobreseimiento definitivo fue el del dos de noviembre de 1931 contra desconocidos porque el Juzgado Primero consideró que con la investigación no se demostró el cuerpo del delito y tampoco se definió si el feto encontrado era o hubiera sido fruto o consecuencia de la actividad humana punible para que pudiera estimarse como delito. Según este juzgado, en los casos de aborto era necesario saber las causas determinantes, porque no solamente pudieron ser provocados sino por motivos de origen patológico. Y, además, aunque fuera hallada la mujer y se dedujera su responsabilidad no se podía hacer nada porque el fenómeno de la prescripción se había consumado, pues el máximo de la pena aplicable sería de cuatro años según el artículo 105 del Código Penal de $1936^{34}$.

En el caso denunciado por Raúl G. se consideró que el juicio no debía continuar porque no se demostró el cuerpo del delito ni la responsabilidad de los acusados; además, la investigación no podía basarse en un informe suministrado por un individuo "indigno de credibilidad" ya que era enemigo de la sindicada. El tribunal consideró que el denunciante no era una persona de confiar porque, aunque había comparecido anteriormente ante la justicia como

\footnotetext{
CDHIR-AHJB, Penal Homicidios, Caja 27, Expediente 555, f. 29.

33 CDHIR-AHJB, Penal Homicidios, Caja 152, Expediente 2619, f. 29.

34 CDHIR-AHJB, Penal Homicidios, Caja 83, Expediente 1555, f. 8.
} 
presunto responsable del delito de estupro cometido en Carmen R. por el cual sufrió detención preventiva, siguió sin el consentimiento de su madre, teniendo relaciones carnales con la muchacha estando embarazada ${ }^{35}$.

Algunos procedimientos penales terminaban en prescripción porque transcurrían más de cinco años desde el momento en que se había realizó el hecho imputado. La diferencia entre sobreseimiento definitivo y prescripción era que en el primero se comprobaba la inocencia del acusado, en cambio en el segundo el caso se cerraba por el transcurrir del tiempo, pero mantenía la culpabilidad de los sindicados.

El Juzgado Primero Superior determinó que la declaración de Griselda M. contra Isabel M. y Adela R. fue creíble, ya que puso a Dios como testigo y, además, puntualizó en algunos hechos y en el careo sostuvo los cargos iniciales. Sin embargo, no se pudo concretar el delito porque habían transcurrido cuatro años desde que los hechos se habían llevado a cabo. En las investigaciones sobre el delito de aborto, existía la dificultad de comprobar el cuerpo del delito porque los rastros y las señales desaparecían con facilidad y rapidez siendo imposible constatar el elemento primordial. Sin el cuerpo del delito no se podía procesar a nadie y por esta razón el juzgado declaró prescrita la acción penal después de nueve años ${ }^{36}$.

\section{Conclusiones}

El aborto en la ciudad de Bucaramanga se pretendió controlar a través de las normas que estaban establecidas en los códigos penales a nivel nacional por las élites políticas; sin embargo, podemos notar que, aunque los órganos judiciales de la ciudad llevaron a cabo los procedimientos dentro del marco legal constitucional, no pudieron castigar a ningún sindicado o señalar puntualmente su culpabilidad. Por tal motivo, se habló sobre un estado de vigilancia, mas no de castigo hacia el hecho imputado. Esta acción era iniciada la mayoría de las veces por los mismos ciudadanos quienes denunciaban a mujeres, comadronas, enfermeras y boticarios de haber realizado el acto criminal; sus testimonios eran basados en los cambios físicos y mentales que observaban en la presunta criminal o en los relatos que otras personas contaban sobre los hechos.

Además, las investigaciones se vieron obstaculizadas por la falta de herramientas científicas y porque los rastros y huellas del delito desaparecían rápidamente en el ambiente. Sumado a esto, percibimos la precariedad de los reconocimientos médico-legales basados en exámenes clínicos que tenían como punto de partida el relato de las mismas mujeres sindicadas porque no tenían

35 CDHIR-AHJB, Penal Homicidios, Caja 83, Expediente 1555, f. 25.

36 CDHIR-AHJB, Penal Homicidios, Caja 83, Expediente 1545, f. 25-30. 
acceso a exámenes de laboratorio que pudieran aclarar lo sucedido. También encontramos la ineficacia de las autoridades judiciales para resolver los casos, lo que daba como resultado la prescripción de la acción penal porque no se realizaba dentro del tiempo estimado, o el sobreseimiento definitivo por no encontrarse el cuerpo del delito.

Sin embargo, el acercamiento a los documentos producidos por el sistema judicial sobre el aborto nos dio la oportunidad de descubrir algunas relaciones sociales y económicas que se estaban llevando a cabo en los sectores populares de la ciudad, entre ellas, la industria tabacalera que configuró el entorno familiar bumangués en donde las condiciones laborales eran poco favorables para sus trabajadores que tenían un bajo salario y en la cual la mayoría de sus trabajadores eran mujeres que aprendían este arte por sus madres. También nos vimos enfrentados ante la relación que existía entre los ciudadanos y los boticarios, comadronas y enfermeras a quienes se les confió su estado de salud y quienes conocían los procedimientos y circunstancias para producir un aborto, o que al realizar procedimientos peligrosos en mujeres que se encontraban en estado de embarazo terminaban en aborto.

Con base en la historiografía y en el análisis del discurso pudimos sumergirnos en la cotidianidad femenina de las mujeres humildes que eran sindicadas como presuntas criminales notando que existían prejuicios por parte de los jueces hacia este grupo social; estas mujeres eran catalogadas como seres inferiores; estos prejuicios también anidaban en la mente de las personas que hacían parte del entorno social de los sindicados que señalaban a las mujeres marginadas, abandonadas por sus maridos o que migraban a la ciudad en condiciones precarias; estas, víctimas de los rumores y el chisme de sus vecinos, fueron las principales protagonistas de los sumarios judiciales.

Esta investigación aporta al afán de algunos investigadores por ofrecerles a los sectores populares una mejor calidad de vida y consciencia de su sexualidad. También se reconoce que el rechazo hacia el aborto, más que un problema de salud pública, hace parte de la imagen que la sociedad conserva hacia la mujer como madre reproductora. Así nos muestra una investigación reciente sobre el aborto en América Latina y el Caribe que señala cómo sus contextos de ilegalidad y penalización han expuesto a las mujeres a riesgos sociales, médicos, psicológicos y jurídicos, que que incrementan cuando las condiciones en las que tiene lugar la práctica no son las adecuadas, cuando carecen de apoyo social o no disponen de recursos e información confiable y de calidad para la toma de la decisión (López, 2015, p. 20). 


\section{Referencias bibliográficas}

Abadía, G. (2006). La legitimidad del derecho penal frente al delito de aborto. Bogotá: Tesis de Maestría en Derecho, Universidad de los Andes.

Álvarez, R. (2012). Organismos estatales de justicia y policía en la ciudad de Bucaramanga, 1900-1950. Anuario de historia regional y de las fronteras. Vol. XVII. N. ${ }^{\circ}$ 2, 319-346.

Álvarez, R. y Ramírez, N. (2013). Perspectivas históricas sobre la criminalidad y los conflictos sociales en Bucaramanga, siglo XX. Bucaramanga: Dirección Cultural Universidad Industrial de Santander.

Betancur, C. (2006). La distancia entre el discurso jurídico y la práctica del aborto en Colombia. Opinión Jurídica-Universidad de Medellín. Vol. 5. N. ${ }^{\circ}$ 10, 1-17. Obtenido el 7 de octubre de 2013 de la base de datos: http://revistas.udem.edu.co/index.php/opinion/article/view/126/110

Cabanellas, G. (1945). El aborto: su problema social, médico y jurídico. Buenos Aires: Editorial Atalaya.

Código Penal de los Estados Unidos de Colombia (ley 112 de 26 de junio de 1873), Bogotá: Imprenta de Medardo Rivas.

Del Valle Montoya P. y Hernández, O. (2010). Aborto y delitos sexuales en Antioquia a finales del siglo XIX y principios del XX: una historia secreta. Revista Estudios de Derecho. N. ${ }^{\circ}$ 67: V. 149, 1-26. Obtenido el 3 de octubre del 2013 de la base de datos: http://aprendeenlinea.udea.edu.co/revistas/index. $\mathrm{php} / \mathrm{red} / \mathrm{article} / \mathrm{view} / 8635 / 7969$.

Dilthey, W. (1999). Dos escritos sobre la hermenéutica. España: Istmo.

Foucault, M. (1996). La verdad y las formas jurídicas. Barcelona: Editorial Paidós.

Franco, H. (1955). El aborto. Bogotá: Tesis de Derecho, Facultad de Jurisprudencia del Colegio Mayor nuestra Señora del Rosario.

Gaceta Judicial de Santander (1930-1946). Rama Judicial. Bucaramanga: imprenta del departamento.

Gómez, B. (2006). Desarrollo del pensamiento jurídico colombiano perspectiva histórica del derecho penal en Colombia. Revista Diálogos de Saberes. N. ${ }^{\circ}$ 24. Obtenido el 10 de enero de 2014 de la base de datos: http://www.unilibre.edu.co/dialogos/admin/upload/index.php?act=view\&id=161.

Gutiérrez, N. (2009). Los delitos de aborto e infanticidio en Antioquia, 1890-1930. Historia y Sociedad. N. ${ }^{\circ} 17,159-177$. Obtenido el día 3 de octubre de 2013 de la base de datos: http://bibliotecavirtual. clacso.org.ar/Colombia/fche-unal/20110510120015/6.pdf

Henderson, J. (2006). La modernización en Colombia, Los años de Laureano Gómez 1889-1965. Medellín: Editorial Universidad de Antioquia.

Hurst, J. (1998). La historia de las ideas sobre el aborto en la iglesia católica: lo que no fue contado. México: Católicas por el Derecho a Decidir.

Las Siete Partidas del rey don Alfonso, El Sabio. (1808). Madrid: Imprenta Real.

Leyes expedidas por el Congreso Nacional en su legislatura del año de 1931. Sesiones ordinarias. Bogotá: Imprenta Nacional.

López, A. y Ramos, S. (2015). Investigación sobre aborto en América Latina y el Caribe: una agenda renovada para informar políticas públicas e incidencia. Ciudad autónoma de Buenos Aires: Centro de Estudios de Estado y Sociedad CEDES; México, DF: population Council; Lima: Promsex. 
Luna, L. y Villarreal N. (1994). Historia, género y política, Movimiento de mujeres y participación política en Colombia, 1930-1991. Barcelona: Universidad de Barcelona.

Martínez, L. (1972). Derecho penal sexual. Tomo I. Bogotá: Editorial Temis.

Molina, C. (2006). El derecho al aborto en Colombia. Medellín: Sello Editorial Universidad de Medellín.

Ortega, J. (1937). Código Penal y Código de Procedimiento Penal. Con notas, concordancias, jurisprudencia de la Corte Suprema y del Tribunal de Bogotá y normas legales complementarias. Bogotá: Editorial Temis.

Peñas, A. (2006). Utilitarismo y tradicionalismo en la legislación penal republicana: el Código de 1837. Revista Colombiana de Sociología. V. 26, 9-42. Obtenido el 10 de enero de 2014 de la base de datos: http://www.revistas.unal.edu.co/index.php/recs/article/viewFile/11383/12046.

Recopilación de leyes de la Nueva Granada. Código Penal de 1837, Bogotá: Imprenta Nacional.

Revista Judicial de Bucaramanga (1930-1946). Organo del Tribunal Superior. Bucaramanga: imprenta del departamento.

Reyes, C. (1995). Cambios en la vida femenina durante la primera mitad del siglo XX. Revista Credencial Historia. N. ${ }^{\circ}$ 68. Obtenido el 1 de octubre de 2013 desde: http://www.banrepcultural.org/ blaavirtual/revistas/credencial/agosto95/agosto3.

Reyes, C. (1996). Al traspasar los muros de la casa: aspectos de la vida femenina en Medellín, 19001930. Boletín Cultural y Bibliográfico. Vol. 31, N. ${ }^{\circ}$ 37, 1-29. Obtenido el 2 de octubre de 2013 desde: http://www.banrepcultural.org/blaavirtual/publicacionesbanrep/boletin/boleti1/bol37/ rese3_3.htm.

Rúgeles, Bartolomé. Diario de un comerciante bumangués 1899-1938 (2005). Transcrito por Aida Martinez Carreño. Bucaramanga: Cámara de comercio de Bucaramanga.

Speckman, E. (1997). Las flores del mal. Mujeres criminales en el porfiriato. Historia mexicana. Vol. 47, N. ${ }^{\circ}$ 1, 183-229. Obtenido el 24 de mayo de 2016 desde: http://codex.colmex.mx:8991/exlibris/aleph/ a18_1/apache_media/15KYCG4UN5CDRF42CMCFJ5TY56GL6K.pdf

Spicker, J. (2000). El cuerpo femenino en cautiverio: aborto e infanticidio entre las esclavas de la Nueva Granada 1750-1810. Geografía humana: los afrocolombianos. Vol. 7. Obtenido el día 1 de octubre de 2013 desde: http://www.banrepcultural.org/blaavirtual/geografia/afro/cuerpo

Surbled, J. (1950). La moral en sus relaciones con la medicina y la higiene. Barcelona: Sucesores de Juan Gili.

Triana, A., Soto, C., y Peña, J. (2012). El derecho a la vida de los no nacidos. Magistro. Vol. 6. N. ${ }^{\circ} 11,87-99$. Obtenido el 17 de octubre de 2013 desde: http://dialnet.unirioja.es/servlet/ articulo?codigo $=3991563$.

Uribe, J. (1900). Jurisprudencia colombiana. Bogotá: Imprenta Nacional.

Valdivieso, S. (1992). Bucaramanga Historias de 75 años. Bucaramanga: Cámara de Comercio. 